\title{
Sustainable supply chain networks - a new approach for effective waste management
}

\author{
H. Winkler \& B. Kaluza \\ Department of Production/Operations Management/Business Logistics \\ and Environmental Management, University of Klagenfurt, Austria
}

\begin{abstract}
In order to realise sustainable development, sufficient waste management is rather important. It is inappropriate for the future only to reduce waste and save energy. Sustainable economic growth is necessary for prosperity but this also in turn causes waste. Based on the literature and formal empirical research, we can state that a movement towards sustainability is only possible if we manage to develop concepts that integrate economic and ecological goals. These challenges can be realised best with the application of certain Sustainable Supply Chain Networks and supply chain management methods. The set up of Sustainable Supply Chain Networks strongly supports the realisation of a circular economy by way of closing process chains between enterprises within an industry and by implementing joint environmental protection measures. This significantly enables the avoidance and reduction of waste and saves costs as well as improves the competitiveness of the members.

Keywords: waste management, waste avoidance, waste reduction, sustainability, Supply Chain, Sustainable Supply Chain Network.
\end{abstract}

\section{Introduction}

Reducing and/or avoiding waste was already an important issue since the early 1970s. Initially, waste was reduced by end-of-pipe-technologies, followed by process- and product-integrated environmental technology developments in the 1980s [1]. These concepts were isolated applications that focussed on a single enterprise.

Today, waste management has to be considered in the context of sustainable development. Sustainable development claims the simultaneous improvement of 
economic, environmental, and social conditions. This means in turn for the business to construct a certain circular economy, where it is that used products, scrap, residuals, and other waste materials are collected, conditioned, and reused or recycled. A single enterprise cannot implement and run a closed circular economy effectively for itself. Holistic waste management can be realised best with the application of certain Sustainable Supply Chain Networks (SSCN). With the methods from supply chain management, a sustainable circular economy is created by closing process chains between companies in an industry and by taking joint economical and ecological useful measures.

In our contribution, we will present an approach for the implementation of a SSCN. Therefore, we will characterise different forms of waste and discuss the reasons for waste emergence. In the next step, some general proposals for waste management will be set forth. Subsequently, we introduce the concept of SSCN and demonstrate the economic and ecological benefits for participating enterprises.

\section{Types and emergence of waste along the product life cycle}

Producing, distributing, and consuming products [2] cause an enormous amount of various types of waste. Within production, various types of waste emerge. Initially, there are waste materials and by-products as a direct result of the transformation processes [3]. In addition, scrap arises as a result of not achieving the required output specifications. Finished and semi-finished goods as well as raw materials require certain packaging that fulfils different functions, such as protection, transport, storage, selling, or easier handling and usage [4]. The lack of the adoption of not re-usable packaging is responsible for most of the generated waste and counts for approximately half of the emerging waste volume in Western Europe [5, 6, 7]. At the end of the life cycle, used products are mostly disposed of by the original user. Hence, they have to be reused, recovered, disposed of, or incinerated.

The emergence of waste is assignable to the product life cycle, which can be divided into three stages: the development-, production- and disposal-stages [8]. From the strategic perspective, the development stage has significant implications for the subsequent life cycle stages. Decisions made during development determine the amount and quality of the generated waste. The configuration of the product properties results in determining most of the used processes, materials, and possibilities to recover and to reuse $[9,10]$. Therefore, it is the most effective way for avoiding waste. The waste that appears in the production stage is highly influenced by the specifications of a product, production processes, and production technologies.

Frequently, waste in the production stage emerges as a result of not having effective processes and/or technologies. The use of hard tooling, e.g. milling, drilling, grinding, or lathing manufacturing processes determines the emergence of waste. Soft tooling processes, e.g. laser sintering or stereo lithographic processes, can be used in order to minimise waste materials. In addition, apart from the used technologies and processes, the efficiency of the transformation 
processes specifies the amount of generated waste. The appearance of scrap emerges due to a mismanaged process or inappropriate processing methods.

A lot of waste along the product life cycle is derived from bad coordinated production and logistics processes, as well as from information deficits between the supply chain members. Bad coordinated logistic processes and a lack of information all lead to the so-called "bull-whip-effect" [11]. This causes overproduction and unnecessary inventory. Overproduction means that production has commenced excessively early and/or too many units have been produced. This generates longer lead times and spoilage. The use of suitable packaging systems can avoid almost half of the waste volume as mentioned above. Therefore, it is tremendously important to use re-usable packaging systems or at least minimise packaging along the entire supply chain. This also includes the consumer packaging that should be considered from the very beginning of the product life cycle to ensure a materially efficient approach.

The disposal stage is characterised through the transition of a good to waste. This stage normally begins when the original user no longer needs the product and chooses to dispose of it. Hence, it should be solicited to prolong the life cycle or intensify the service units provided to minimise the waste impact. Therefore, the emergent waste should be reusable or recyclable in order to achieve a high degree of sustainability $[10,12]$.

\section{Waste management in the context of a circular economy}

There are three main reasons for enterprises to make efforts in improving their waste position: 1) If the waste producers are charged for the full environmental cost, it in turn becomes more cost-effective to reduce the amount of waste they produce, 2) it can be profitable to reduce waste because the raw material charge also decreases and 3) an improved environmental position can strengthen customer loyalty, which is beneficial in a favourable market position.

For effective waste management the types and reasons of emerging waste have to be detected. The amount of produced waste is a consequence of how effectively and efficiently we use resources, and once waste has been produced, how it is dealt with has a strong impact on the environment. Most of the generated waste can be avoided and/or recovered by constructing a circular economy.

In order to realise a circular economy, every type of waste has to be a part of a closed loop process chain. Therefore, companies have to provide a framework for realising a circular system. In detail, an integrated reuse and recovery system must be organised and implemented to ensure adequate waste treatment. Consequently, waste management has considerable impacts on the competitiveness and profitability of an enterprise [13].

The principles of waste management are elimination, reduction, reuse, recovery, and disposal of waste, whereas elimination has the highest priority, and disposal has the lowest priority $[12,14,15,16]$. For realisation, the principles of waste management enterprises are forced to close open process chains. This means that most of the generated waste has to be returned to the manufacturing 
or consuming processes. In this context, the best solution is reusing waste because there is no need for additional material input. When reusing is impossible, waste should be recovered in a recycling process to guarantee a circular flow. This advances the material efficiency as well as the positive impact on the environment because only a minimum of the produced goods and waste must be assimilated by the environment. Incineration or disposal should be avoided because the waste materials have to be replaced by new material inputs.

\section{Application of Sustainable Supply Chain Networks for the avoidance and reduction of waste}

In business, waste management is often seen as a duty of a single company [17]. We reject this limited view and suggest, due to the aforementioned facts, to configure a SSCN to realise a circular economy and construct a closed loop waste management. We think that a SSCN configuration is a holistic approach to avoid and reduce waste and gain economic advantages for members.

\subsection{Organisation and structure of a Sustainable Supply Chain Network}

A SSCN is a set of different types of companies that work together to realise a sustainable circular economy considering the potentials for waste reduction and avoidance from the development stage to the end-of-life of the life cycle of a product.

With the forming of a circular economy, the various process chains of all members of the network should be closed to avoid and reduce waste. With closing the process chains, the share of recycled materials can be increased up to 80 per cent, instead of 1 per cent with unclosed process-chains [8].

The main principles of the SSCN refer to a sustainable configuration of the network. Therefore, it is necessary to set up sustainable goals and strategies, formulate and introduce sustainable win-win relationships, implement intelligent systems and resources, as well as arrange cooperative R\&D with focus on sustainability. These principles influence and interact with each other and must be coordinated to establish an effective and efficient SSCN.

The participants of a SSCN are not only companies of an existing supply chain, but also service providers specialised in collecting, exchanging, conditioning, recycling, or eliminating used products and waste [18]. These companies adopt duties for remanufacturing/reuse, recycling and disposal/incineration to enable a circular economy in the SSCN. In addition, special logistics providers are integrated to manage the physical distribution and redistribution of the material flows between the participants. Furthermore, together with the service providers they are also responsible for collecting, saving, and analysing waste specific information and providing them to the participants of the network. In Figure 1 shows exemplarily the relationships between the enterprises of a SSCN. These relationships include the information-, material-, residual-, used product-, waste- and financial exchange processes among all of the companies. 


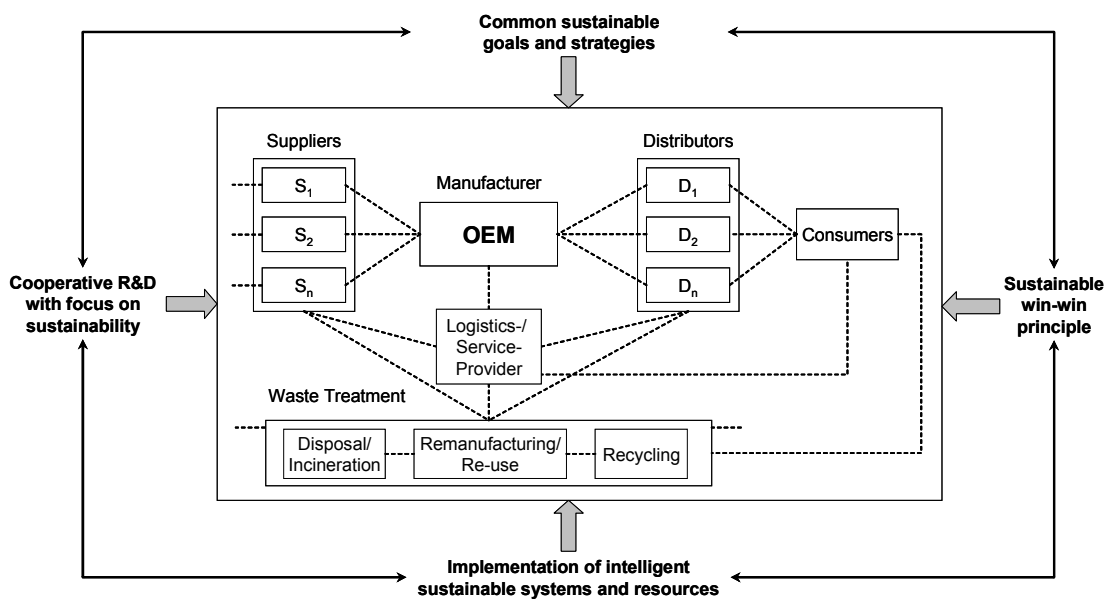

Figure 1: Generic structure and principles of a Sustainable Supply Chain Network.

Within the SSCN, two main planning levels have to be considered. The first planning level corresponds to the network-level, the second to the enterpriselevel. To run a circular economy the companies formulate environmental goals, strategies, measures and measurement principals for co-operation on the network-level in common.

Preventing and reducing ecological mismanagements such as wasting energy and resources by organising closed process chains and gaining economical benefits are goals of the SSCN. Strategies to accomplish the determined goals among all of the companies have to be formulated. These strategies refer to recycling, reusing, remanufacturing, as well as on product development. Deriving from these strategies, the appropriate measures and metrics have to be set on the enterprise-level. Purchasing, marketing, distribution, logistics, and operational measures have to be set within the enterprises, involving all corporate divisions and value creating activities $[19,20]$. It is here that the main restriction on the enterprise-level, which is the sustainable goals of the network, must not be in conflict with the concrete strategic and operative goals of a single enterprise. In fact, the companies remain legally and economically independent, making their own strategic and operational decisions influenced by the network strategies.

The implementation of a SSCN leads to the strong improvement of the competitiveness of all participants of the network as well as to an increase of all the companies' values. This is based on the higher efficiency of the used resources as well as on the value of the remaining waste. An improvement of most of the ecological and economical results is a realistic consequence. Firstly, this is evident because the production of waste and residuals is avoided at the development stage of the product life cycle where it is economically and ecologically useful. Secondly, when waste is a valuable good for one or more members of the SSCN, this waste is no longer only garbage, but a sellable good. 


\subsection{Possibilities for waste avoidance and waste reduction}

One target of implementing a SSCN is to avoid waste along the entire product life cycle. Identifying all of the factors that influence the existence and the emergence of waste at every member of the supply chain is very important to reach this objective. In fact, proactive SSCN management begins in the stage of $\mathrm{R} \& \mathrm{D}$, in the conceptual design-phase of the product. Decisions that are made in this life cycle stage have the most significant influence on the product life cycle costs and on preventing environmental costs at the disposal stage of the product $[9,10]$.

Integrating the SSCN partners in this early stage of product development prevents the conception of a product that contains hazardous (toxic), nonreusable, or non-recyclable materials [9]. With this measure, bad economic and ecological results for various members of the network are avoided. The major objective of cooperative $R \& D$ is to find the possibilities to prevent waste and save resources. Not only materials and other factors for production are determined at the developing stage. Furthermore, this stage has effects on the product design (shape) and the packaging. Designing a product that is constructed for an easy dismantling makes it easier to avoid waste that is not reusable. Connecting this with developing a packaging-free product and/or reusable packaging systems where it is technologically, economically, and ecologically possible, avoids packaging waste. The usage of reusable packagingsystems has economic and ecological advantages for the entire supply chain network because of standardising the logistical interactions between the SSCN participants. Reusable packaging systems can be implemented in the distribution and redistribution of the materials and goods. For developing these packaging systems, the knowledge and expertise of the recycling-companies and the logistic service providers has to be used. Specialised in managing the transportation, handling, storekeeping, collecting, and packaging of materials and goods, logistic-service-providers know various options to avoid waste in an effective way. The recycling companies are acquainted with the possibilities to disassemble all of the products or semi-products of the supply chain. Consequently, they can provide the essential information of how the producers can design the products and their components free of waste.

Cooperative developing of ecological and waste free products is not the only reason for joining a SSCN. The possibility to use resources of the networkpartners is another reason for participating. It is here that the focus is on the available tangible and intangible resources of the partners. In co-operation with the partners, previous production technologies and techniques could be improved to eliminate waste and raise productivity. Similar technologies that have already successfully been implemented in enterprises could be transferred to the other companies.

Apart from the proposed methods to prevent the production of waste, the enterprises have to analyse their processes, methods, and products to reduce existing waste significantly. Analysing the production and logistics processes within a company to find potential for ecological improvements is an option for 
reducing waste. The main objective here is to increase the efficiency of processes, for example, by improving the use of materials and other production factors in the manufacturing process. Especially packaging waste can be reduced by using larger or standardised packaging-units.

Apart from the processes, the used resources for procurement, manufacturing, distribution, and redistribution also have to be dissected. With a change in the handling of some waste intensive production and logistics devices scrap can be decreased [19, 21]. Therefore, manufacturing technologies in the SSCN should operate in a way that no wastefulness of materials and semi-finished goods occur at any stage. Another opportunity to reduce waste is to prolong the product life. The exchange of spare parts/consumable parts of the products as well as preventive maintenance are services that extend the life of products significantly.

Additionally, improving the planning systems and activities are opportunities for cutting waste. With coordinated planning methods, it is possible to predetermine the quantities of materials needed for manufacturing more precisely.

\section{An example for the reduction of waste by using a kind of Sustainable Supply Chain Network}

For illustrating the benefits of a SSCN, it is suitable to choose an industry that works diligently to achieve the goal of sustainability. Within the automotive industry, many enterprises exist that have introduced environmental initiatives for gaining a competitive advantage towards sustainability. Consequently, the automobile is the consumer article with the highest rate of recycling, which is even higher than paper [22].

From 2006 at least $85 \%$ and from 2015 at least $95 \%$ of the average weight of an end-of-life vehicle must be recovered whilst the remaining materials may be disposed of. Over $80 \%$ accordingly $85 \%$ of the total recovery quota is taken up by reuse and recycling whilst the proportion of incineration is restricted to a maximum of $5 \%$ accordingly $10 \%$ of the average weight per vehicle [23].

For achieving these targets, enterprises have to implement a closed-loop waste management system, which must be organised by integrating all of the participants along the supply chain. This means that all of the possible waste flows during the product-life-cycle must be considered. With this framework, it is possible to generate a synergetic result, which means that all of the waste flows are planned by a central logistics-/ service-provider.

Figure 2 shows a possible flowchart of a disassembly and utilisation system in connection with a SSCN in the automotive industry. Many different processes have to be regarded and planned. Therefore, the service-provider has to coordinate the different material and waste flows to secure an optimum in recovering the end-of-life products, in this case used cars. In addition to the material flow activated by the origin supply chain, this process results in high material efficiency.

Running the recovery facilities at full capacity, and cutting the overall recovery costs; different manufacturers should consider aligning their recovery 
processes [23]. For this reason, it should be possible to create a SSCN where all of the participants are able to reach a high degree of competitiveness regardless of the examined industry. Therefore, the manufacturers are able to decrease their material inputs and to realise the required recovery quota. The enterprises involved in waste treatment can optimise their processes because of having a high equipment utilisation, which results from the coordinated waste flows.

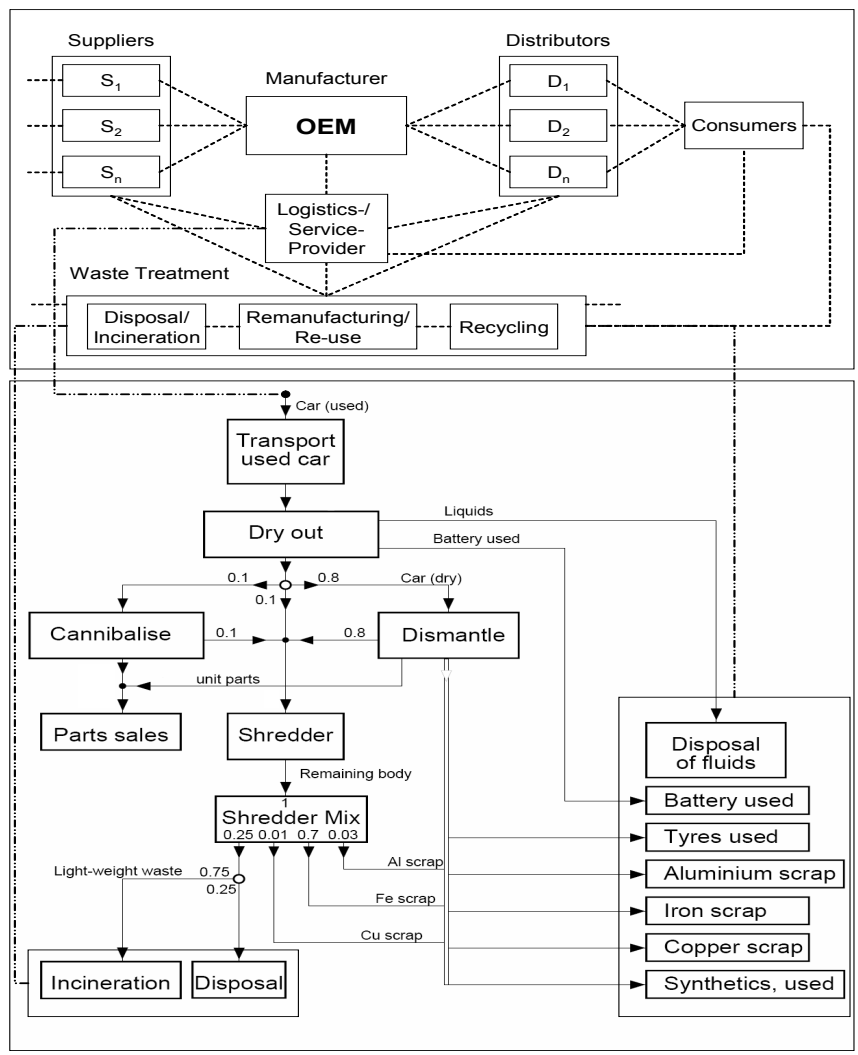

Figure 2: $\quad$ A part of SSCN in the automotive industry.

\section{Conclusion}

In our contribution, we highlighted the actual deficits of waste management and claimed the possibility to construct a SSCN in order to implement an integrated waste management. With a SSCN, it is possible to turn from a flow economy to a closed loop economy. This benefits ecological and economic development within the SSCN, which leads to the improvement of the competitive position for all participants.

We have shown that four principals are essential to reach a sustainable configuration of the SSCN. These are the setting up of sustainable goals and 
strategies, formulating and introducing sustainable win-win relationships, implementing intelligent systems and resources, as well as arranging cooperative R\&D with a focus on sustainability. These strategic principals shape the SSCN, its specific configuration, and the relationships between the participating enterprises. As we have demonstrated, the members of the SSCN are not only companies of the origin supply chain. Remanufacturing/Re-use, Recycling, and Disposal/Incineration enterprises, but also logistics and service providers are important partners in a SSCN.

In example, we demonstrated that in the automotive industry legal changes occurred that encourage automotive manufacturers to introduce a circular economy. Meeting the legal requirements and achieving economic advantages is only possible by constructing a SSCN.

Future research in this area must focus on the practical implementation of the concept of SSCN. Measurement-systems must be developed and verified for steering the SSCN effectively and efficiently. Within empirical projects, the validity of the stated arguments has to be tested.

\section{References}

[1] Nagel, M. H., Managing the environmental performance of production facilities in the electronics industry: more than application of the concept of cleaner production, Journal of Cleaner Production, 11(1), pp. 11-26, 2003.

[2] Feser, H.-D., Vom End-of-Pipe zum Integrierten Umweltschutz? Die volkswirtschaftliche Perspektive. Integrierter Umweltschutz. Umwelt und Ressourcenschonung in der Industriegesellschaft, eds. H.-D. Feser, W. Flieger \& M. v. Hauff, Transfer Verlag: Regensburg, pp. 41-56, 1996.

[3] Dijkema, G. P. J., Reuter, M. A. \& Verhoef, E. V., A new paradigm for waste management. Waste Management, 20(8), pp. 633-638, 2000.

[4] Souren, R., Konsumgüterverpackungen in der Kreislaufwirtschaft. Stoffströme-Transformationsprozesse-Transaktionsbeziehungen, neue betriebswirtschaftliche forschung 293, Deutscher Universitäts-Verlag: Wiesbaden, pp. 40-43, 2002.

[5] Europäische Kommission, Im Visier der EU: Abfallwirtschaft, Amt für amtliche Veröffentlichungen der Europäischen Gemeinschaften: Luxemburg, p. 11, 2000.

[6] Kogg, B., Power and Incentives in Environmental Supply Chain Management. Strategy and Organization in Supply Chains, eds. St. Seuring, M. Müller, M. Goldbach \& U. Schneidewind, Physica-Verlag: Heidelberg New York, pp. 65-82, 2003.

[7] Cardinali, R., Waste management: a missing element in strategic planning. Work Study,50(5), pp. 197-201, 2001.

[8] Blecker, Th., Logistische Aspekte der Kreislaufwirtschaft. Kreislaufwirtschaft und Umweltmanagement. Duisburger Betriebswirtschaftliche Schriften Band 17, ed. B. Kaluza, S + W Steuerund Wirtschaftsverlag: Hamburg, pp. 97-134, 1998. 
[9] Waage, S. A., Reconsidering product design: a practical "road-map" for integration of sustainability issues. Journal of Cleaner Production, Article in Press, Corrected Proof, pp. 1-12, 2006.

[10] Maxwell, D. \& v. d. Vorst, R., Developing sustainable products and services. Journal of Cleaner Production, 11(8), pp. 883-895, 2003.

[11] Wildemann, H., Supply Chain Management. Effizienzsteigerung in der unternehmensübergreifenden Wertschöpfungskette. TCW-report 39, TCW Transfer-Centrum: München, pp. 14-19, 2003.

[12] Bates, M. P. \& Phillips, P. S., Sustainable waste management in the food and drink industry. British Food Journal, 101(8), pp. 580-589, 1999.

[13] V.Hoek, R. I., From reversed logistics to green supply chains. Supply Chain Management, 4(3), pp. 129-134, 1999.

[14] Kumar, S. \& Malegeant, P., Strategic alliance in a closed-loop supply chain, a case of manufacturer and eco-non-profit organization. Technovation, Article in Press, Corrected Proof, 2005.

[15] Ravi, V., Shankar, R. \& Tiwari M. K., Productivity improvement of a computer hardware supply chain. International Journal of Productivity and Performance Management, 54(4), pp. 239-255, 2005.

[16] McDougall, F. R., Life Cycle Inventory Tools: Supporting the Development of Sustainable Solid Waste Management Systems, Corporate Environmental Strategy, 8(2), pp. 142-147, 2001.

[17] Shen, J.-B., Chou, Y.-H. \& Hu, Ch.-Ch., An integrated logistics operational model for green-supply chain management. Transportation Research Part E: Logistics and Transportation Review, 41(4), pp. 287313, 2005.

[18] Prahinski, C. \& Kocabasoglu, C., Empirical research opportunities in reverse supply chains. Omega, 34(6), pp. 519-532, 2006.

[19] Rao, P. \& Holt, D., Do green supply chains lead to competitiveness and economic performance?. International Journal of Operations \& Production Management, 25(9), pp. 898-916, 2005.

[20] Hervani, A. A., Helms, M. M. \& Sarkis, J., Performance measurement for green supply chain management. Benchmarking: An International Journal, 12(4), pp. 330-353, 2005.

[21] Rao, P., Greening the supply chain: a new initiative in South East Asia. International Journal of Operations \& Production Management, 22(6), pp. 632-655, 2002.

[22] Schweimer, G. W. \& Levin, M., Life Cycle Inventory for the Golf A4, www.volkswagensustainability.com/nhk/nhk_folder/en/download.Par.002 2.Download.pdf

[23] Krinke, S., Boßdorf-Zimmer, B. \& Goldmann. D., Executive Summary Life Cycle Assessment of End-of-Life Vehicle Treatment, www.volkswagen-

sustainability.com/nhk/nhk folder/en/leistungen/umwelt/recycling/siconverfahren.Par.0002.Download.pdf 